\title{
Involvement of 5-hydroxytryptamine type 3 receptors in sevoflurane-induced hypnotic and analgesic effects in mice
}

\author{
Li-Hua Hang ${ }^{1,2}$, Dong-Hua Shao ${ }^{2}$, Hong Wang ${ }^{2}$, Jian-Ping Yang ${ }^{1}$ \\ ${ }^{1}$ Department of Anesthesiology, the First Affiliated Hospital of Soochow University, Suzhou, 215006, PR China \\ ${ }^{2}$ Department of Anesthesiology, the Affiliated People's Hospital of Jiangsu University and the First People's \\ Hospital of Zhenjiang, Zhenjiang, Jiangsu, 212002, PR China
}

Correspondence: Jian-Ping Yang, e-mail: szyangjp@gmail.com

\begin{abstract}
:
In the present study, we investigated the role of 5-hydroxytryptamine type $3\left(5-\mathrm{HT}_{3}\right)$ receptors in hypnosis and analgesia induced by emulsified sevoflurane. A mouse model of hypnosis and analgesia was established by an intraperitoneal or subcutaneous injection of emulsified sevoflurane. We intracerebroventricularly (icv) or intrathecally (it) administered YM-31636, a 5-HT 3 receptor agonist, to mice and observed sleep time during hypnosis. In addition, the tail withdrawal latency was measured using the tail withdrawal test, and the writhing time was determined using the acetic acid writhing test. In the hypnosis test, YM-31636 $(5,10$ and $15 \mu \mathrm{g}, i \mathrm{cv})$ treatment significantly decreased emulsified sevoflurane-induced mouse sleep time $(\mathrm{p}<0.05$ or $\mathrm{p}<0.01)$. YM-31636 $(2.5,5$ and $10 \mu \mathrm{g}$, it) treatment significantly and dose-dependently decreased the tail withdrawal latency $(\mathrm{p}<0.05$ or $\mathrm{p}<0.01)$ and increased the writhing time $(\mathrm{p}<0.01)$ of mice treated with emulsified sevoflurane. These results suggest that $5-\mathrm{HT}_{3}$ receptors may modulate the hypnotic and analgesic effects induced by emulsified sevoflurane.
\end{abstract}

Key words:

sevoflurane, hypnosis, analgesia, 5- $\mathrm{HT}_{3}$ receptors

\section{Introduction}

One hundred and sixty years after inhalation anesthetics were adopted into clinical practice, the underlying mechanism of action remains unknown. Recently, ligand-gated ion channels have emerged as the most promising molecular target for inhalation anesthetics $[8,15,23,30]$. Various in vitro studies have reported that enhancement of inhibitory neurotransmitter function or inhibition of excitatory neurotransmitter function is a plausible method to induce anesthesia $[1,30$, $32,33]$.
5-Hydroxytryptamine (5-HT) is a biogenic amine that mediates a variety of physiological actions. 5-HT receptors are classified into seven major groups [9]. Of these subtypes, the $5-\mathrm{HT}_{3}$ receptor is a member of the superfamily of ligand-gated ion channel receptors. This family shares structural similarities with the nicotinic acetylcholine, glycine, and $\gamma$-aminobutyric acid type $\mathrm{A}\left(\mathrm{GABA}_{\mathrm{A}}\right)$ receptors $[3,11,12]$. The $5-\mathrm{HT}_{3}$ receptors are widely distributed in both the central and peripheral nervous system and are involved in the physiologic and pathologic processes that mediate nausea, vomiting, peripheral nociception, and central 
antinociception $[5,20]$. Previous studies have shown that inhalation anesthetics modulate $5-\mathrm{HT}_{3}$ receptors $[25,26]$. Sevoflurane is a halogenated inhalation anesthetic. In vitro electrophysiological studies have demonstrated that sevoflurane inhibits $5-\mathrm{HT}_{3}$ receptors $[16,28]$. Therefore, $5-\mathrm{HT}_{3}$ receptors may confer sevoflurane-dependent anesthesia. Inhalation anesthetics have two main effects, hypnosis and analgesia $[19,24]$. However, whether the $5-\mathrm{HT}_{3}$ receptors are involved in sevoflurane-induced hypnotic or analgesic effects has not been determined in an in vivo behavioral study.

We hypothesized that if $5-\mathrm{HT}_{3}$ receptors contribute to the hypnotic and the analgesic effects of sevoflurane, the application of the $5-\mathrm{HT}_{3}$ receptor agonist YM-31636 (2-(1H-imidazol-4-ylmethyl)-8H-indeno[1,2d]thiazole monofumarate) should decrease the hypnotic and analgesic effects of sevoflurane. We addressed this hypothesis by using the hypnosis test, tail withdrawal test and acetic acid writhing test.

\section{Materials and Methods}

\section{Animals}

Kunming mice $(22 \pm 3 \mathrm{~g})$ were obtained from the Experimental Animal Center of Jiangsu University. Mice were housed in a 12-hour light/dark cycle at room temperature $\left(22 \pm 2^{\circ} \mathrm{C}\right)$. Food and water were provided ad libitum. All experiments were performed between 8:00 and 12:00 to avoid diurnal variation during behavioral testing. The experimental protocols were approved by the Animal Care and Use Committee of Jiangsu University and complied with the National Institutes of Health Guide for Care and Use of Laboratory Animals (Publication No. 85-23, revised 1985).

\section{Formulation of emulsified sevoflurane}

Sevoflurane was emulsified using the method of Chiari et al. [4]. Sevoflurane was dissolved in soy bean oil containing dispersed egg lecithin, which comprised the oil phase of the emulsion. Dissolution of egg lecithin in soy bean oil was facilitated with heat. After dissolution of lecithin, the oil phase was cooled to approximately $10^{\circ} \mathrm{C}$ before addition of sevoflurane.
The aqueous phase of the emulsion contained glycerin. The aqueous phase was cooled to $10^{\circ} \mathrm{C}$. The oil phase was then added to the aqueous phase under vigorous stirring to form the initial emulsion. The initial emulsion was homogenized at high pressure to form the final emulsion. After homogenization, the emulsified sevoflurane was stored in glass vials. Vials were capped and refrigerated $\left(2-5^{\circ} \mathrm{C}\right)$ until further experimentation. Vials of emulsion were warmed to $37^{\circ} \mathrm{C}$ for $2 \mathrm{~h}$ before administration. The target concentration of anesthetics in emulsion was approximately $8 \%$. After warming the emulsion for $2 \mathrm{~h}$ at $37^{\circ} \mathrm{C}$, the actual concentration of sevoflurane in the emulsion was $7.5 \%$, as determined by gas chromatography.

\section{Intracerebroventricular injection}

Intracerebroventricular (icv) administration was performed following the method of Laursen and Belknap [14]. Briefly, animals were injected at the bregma with a $50-\mu 1$ Hamilton syringe fitted with a 26 -gauge needle, which had a tip that was adjusted for 2.4-mm penetration. The icv injection volume was $5 \mu \mathrm{l}$, and injection sites were verified by injecting an equal volume of $1 \%$ methylene blue. Dye distribution into the ventricular space was observed. The dye seeped into the ventricular space, ventral surface of the brain, and the upper cervical portion of the spinal cord.

\section{Intrathecal injection}

Conscious mice were injected intrathecally (it) using the method of Hylden and Wilcox [10]. At the 5th lumbar vertebra a 26-gauge needle fitted with a microsyringe was inserted into the spinal canal at a $30^{\circ}$ angle. Transient tail extension indicated a successful injection. The solution was injected in a volume of $5 \mu \mathrm{l}$ over $5 \mathrm{~s}$. Lidocaine (2\%) was injected it into 10 mice, which immediately exhibited hindlimb paralysis that lasted for approximately $10 \mathrm{~min}$ in the preliminary experiments.

\section{Drug administration}

The hypnotic dose of sevoflurane $(20 \mathrm{ml} / \mathrm{kg})$ was determined in preliminary experiments [6]. Sevoflurane was injected intraperitoneally $(i p)$ to produce hypnosis in mice. Sevoflurane was injected ip $(10 \mathrm{ml} / \mathrm{kg})$ or subcutaneously $(s c)(25 \mathrm{ml} / \mathrm{kg})$ to produce analgesia in mice. 


\section{Hypnosis test}

Forty Kunming mice (male or female) were randomly divided into 4 groups $(\mathrm{n}=10)$ : the emulsified sevoflurane + artificial cerebral spinal fluid (aCSF) groups and the emulsified sevoflurane + YM-31636 (5, 10 and $15 \mu \mathrm{g})$ groups.

Every group was injected $i p$ with a hypnotic dose of emulsified sevoflurane. One minute after loss of the righting reflex (animal remain on their back for at least $30 \mathrm{~s}$ ) the mice were injected $i c v$ with aCSF or YM-31636. Sleep time (duration of the loss of righting reflex) was observed [2].

\section{Tail withdrawal test}

All experiments were started at 10:00 a.m. and performed according to the method of Kayser et al. [13]. Briefly, each mouse was placed in a plastic tube (50 $\mathrm{ml}$ polypropylene conical tube) such that the tail protruded from an opening in the bottom of the tube. The distal half of the tail was dipped into a bath of circulating water that was thermostatically controlled at $48.0 \pm 0.5^{\circ} \mathrm{C}$. The tail withdrawal latency (TWL) was measured by an experienced observer in a single blind manner. A cut off time of $20 \mathrm{~s}$ was used to avoid tissue damage.

Eighty Kunming mice (male or female) were randomly divided into 8 groups $(\mathrm{n}=10)$ : aCSF group; YM-31636 $(2.5,5$ and $10 \mu \mathrm{g})$ groups; the emulsified sevoflurane + aCSF groups, and the emulsified sevoflurane + YM-31636 $(2.5,5$ and $10 \mu \mathrm{g})$ groups. The aCSF and YM-31636 groups were injected it with aCSF and YM-31636, respectively. Groups that received emulsified sevoflurane were injected ip with an analgesic dose. After $5 \mathrm{~min}$, each group was injected $i t$ with aCSF or YM-31636. Baseline TWL and TWL at 5, 10, 15, 20 and 25 min after injection was observed.

\section{Acetic acid writhing test}

Eighty Kunming mice (male or female) were randomly divided into 8 groups $(\mathrm{n}=10)$ : aCSF group; YM-31636 (2.5, 5 and $10 \mu \mathrm{g})$ groups; the emulsified sevoflurane + aCSF groups, and the emulsified sevoflurane + YM-31636 (2.5, 5 and $10 \mu \mathrm{g})$ groups. The aCSF and YM-31636 groups were injected it with aCSF and YM-31636, respectively. The emulsified sevoflurane groups were injected $s c$ with an analgesic dose. After $10 \mathrm{~min}$, each group was injected it with aCSF or YM-31636. One minute after it administration, mice were injected ip with $0.6 \%$ acetic acid $(10 \mathrm{ml} / \mathrm{kg})$. Each mouse was then placed into an individual Plexiglas observation cylinder $(14 \mathrm{~cm}$ diameter; $30 \mathrm{~cm}$ in height). The writhing time (arching of the back, development of tension in the abdominal muscles, elongation of the body and extension of the forelimbs) within $15 \mathrm{~min}$ was recorded after the final injection [31].

\section{Statistics}

Results are expressed as the mean \pm SEM. Data were statistically analyzed using SPSS16.0 software (SPSS Inc., Chicago, IL, USA). Multiple group comparisons were performed by one-way ANOVA followed by the Dunnett's post-hoc test. For the tail withdrawal test, the difference between baseline and drug treatment was analyzed using a paired Student's $t$-test; $\mathrm{p}<0.05$ was considered statistically significant.

\section{Results}

\section{Hypnosis test}

Icv injection of YM-31636 $(5,10$ and $15 \mu \mathrm{g})$ significantly decreased the sleep time of the mice treated with emulsified sevoflurane ( $<<0.05$ and 0.01; Tab. 1).

\section{Tail withdrawal test}

The TWL of conscious mice was not affected by an it injection of YM-31636 (2.5, 5 and $10 \mu \mathrm{g} ; \mathrm{p}>0.05$

Tab. 1. Effects of YM-31636 treatment on the sleep time of mice treated with emulsified sevoflurane in the hypnosis test.

\begin{tabular}{cccc}
\hline Group & $\mathrm{N}$ & Dose $(\mu \mathrm{g})$ & Sleep time (min) \\
\hline aCSF & 10 & - & $58.7 \pm 2.2$ \\
YM-31636 & 10 & 5 & $53.6 \pm 2.3$ \\
& 10 & 10 & $50.3 \pm 2.4^{*}$ \\
& 10 & 15 & $43.1 \pm 1.8^{* *}$ \\
\hline
\end{tabular}

Data represent the mean \pm SEM $\left({ }^{*} p<0.05,{ }^{* *} p<0.01 v s\right.$. aCSF group using one-way ANOVA and Dunnett's test) 

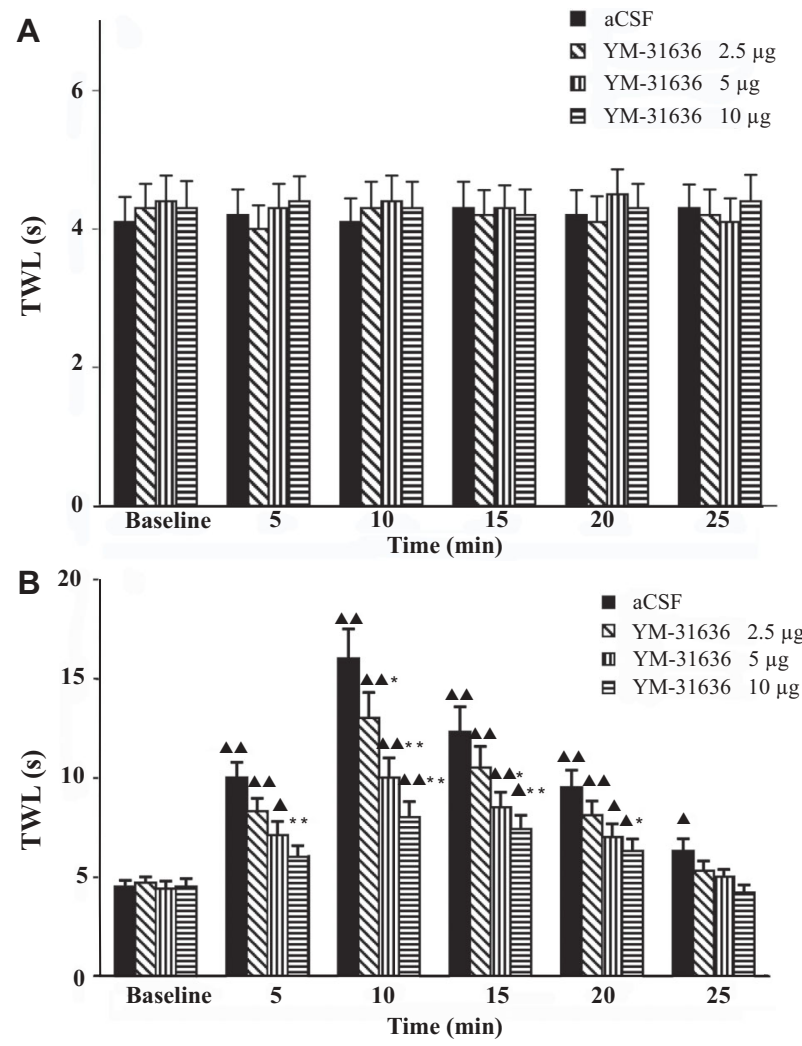

Fig. 1. Effects of YM-31636 treatment on the tail withdrawal latency (TWL) in conscious mice (A) and mice treated with emulsified sevoflurane (B). YM-31636 (2.5, 5 and $10 \mu \mathrm{g})$ was injected it. The data represent the mean \pm SEM. Ten mice were used in each group ${ }^{*} p<0.05$ ${ }^{* *} p<0.01$ vs. aCSF group, using one-way ANOVA and Dunnett's test; $\Delta \mathrm{p}<0.05, \boldsymbol{\Delta} \mathbf{\Delta} p<0.01$ vs. baseline using paired Student's $t$-test)

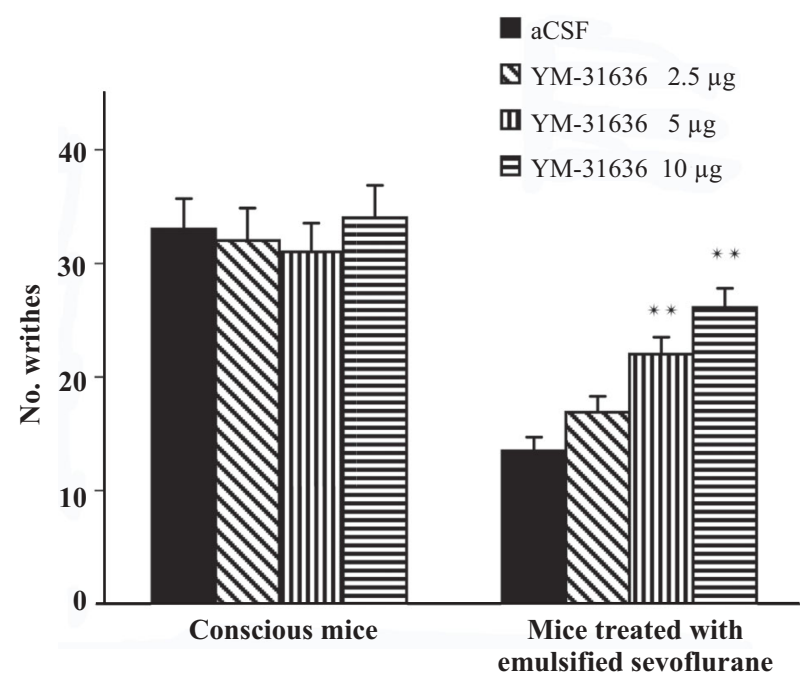

Fig. 2. Effects of YM-31636 treatment on the acetic acid writhing times in mice. YM-31636 (2.5, 5 and $10 \mu \mathrm{g})$ was injected it. The data represent the mean \pm SEM. Ten mice were used in each group ( ${ }^{* *} \mathrm{p}<$ 0.01 vs. aCSF group, using one-way ANOVA and Dunnett's test) compared to the aCSF treatment, Fig. 1A). YM-31636 $(2.5,5$ and $10 \mu \mathrm{g}, i t)$ treatment significantly and dose dependently decreased the TWL $(\mathrm{p}<0.05$ and 0.01 compared to the aCSF treatment) of mice that received an ip injection of emulsified sevoflurane. YM-31636 $(2.5,5$ and $10 \mu \mathrm{g}, i t)$ treatment decreased the TWL by $18.8(\mathrm{p}<0.05), 37.5$ and $50.0 \%(\mathrm{p}<0.01)$, respectively, $10 \mathrm{~min}$ after emulsified sevoflurane injection (Fig. 1B).

\section{Acetic acid writhing test}

YM-31636 $(2.5,5$ and $10 \mu \mathrm{g}, i t)$ treatment did not affect mouse behavior and the writhing time in comparison to the effects of aCSF administration in conscious mice $(\mathrm{p}>0.05)$. In the groups receiving an $s c$ injection of emulsified sevoflurane, YM-31636 $(2.5 \mu \mathrm{g}$, it) treatment did not affect the writhing time. However, YM-31636 (5 and $10 \mu \mathrm{g}$, it) treatment markedly increased writhing time in comparison to mice treated with aCSF ( $p<0.01$, Fig. 2).

\section{Discussion}

Inhalation anesthetics are often administrated through the airway. Administration needs specific types of equipment. Therefore, some inhalation experiments cannot be performed. Novel formulations of inhalation anesthetics have been developed to facilitate drug administration in vivo. These formulations are composed of a drug emulsification in a lipid vehicle. This preparation may be clinically useful to produce anesthesia [4]. Previous studies support the efficacy and safety of the $i v$ administration of emulsified inhalation anesthetics in animals [34, 35]. According to drug pharmacokinetics and our preliminary experiments $[6$, 7], we confirmed that ip and $s c$ injection of emulsified inhalation anesthetics can achieve hypnosis and analgesia similar to that produced by inhalation. In the hypnosis test, hypnotic doses of emulsified sevoflurane induced the loss of mouse righting reflex. Mouse sleep time was approximately $60 \mathrm{~min}$; however, drug treatment minimally affected breathing and blood circulation. In the tail withdrawal test and the acetic acid writhing test, we used an $i p$ or $s c$ injection to produce analgesia. Mice not only showed the effects of analgesia but also had essentially normal be- 
havior and the righting reflex was not lost. To avoid an interaction between the ip injection of emulsified sevoflurane and acetic acid, we chose an analgesic model that used an $s c$ injection of emulsified sevoflurane. Onset velocity measures the absorption velocity from ip or $s c$ injection. Emulsified sevoflurane is absorbed more slowly from an sc injection than from an ip injection. Therefore, the dose of emulsified sevoflurane that was applied to mice in the acetic acid writhing test was greater than that used in the hypnosis test.

General anaesthesia induces immobility, amnesia, hypnosis, and analgesia and the suppression of stress responses to noxious stimuli. To simplify our experiments, individual components of general anesthesia were observed [29]. However, there is a caveat - the effects of anesthesia are not independent. Pain increases awareness. Noxious stimuli during anesthesia increases arousal, as indicated by increased neuronal activity in the reticular formation and thalamus. The spinal cord (responsible for analgesia and anesthesiainduced immobility) interacts with the brain cortex (responsible for awareness and hypnosis).

Inhalation anesthetics supply two essential elements of anesthesia - hypnosis and analgesia. Hypnosis is defined as the lack of 'perceptive awareness', which is assessed by the response to non-noxious stimuli [15]. The righting reflex test determines the ability of an animal to regain an upright posture within $30 \mathrm{~s}$ of being placed in a supine position. In the absence of central nervous system depression or impairment, maintaining an upright posture is a natural reflex. Therefore, this assay is used to test drugs that cause significant central nervous system depression [17]. The tail withdrawal test and acetic acid writhing test are methods to measure analgesia. Analgesia is defined as the loss of pain sensation without loss of consciousness or mobility.

YM-31636 is a novel agonist of the $5-\mathrm{HT}_{3}$ receptor. Treatment with YM-31636 agitates animals and may even produce convulsions. In preliminary experiments, we observed that YM-31636 $(20 \mu \mathrm{g}$, icv) treatment induced scratching and biting behavior. This suggests that the dose used in the hypnosis test was sufficient. In agreement with our hypothesis, we observed that $i c v$ administration of YM-31636 attenuates the hypnotic effects of emulsified sevoflurane. This is also in agreement with the findings of Mukaida et al. [16]. In this study, serotonergic activity modulated the hypnotic effects of isoflurane.
Studies in rats and goats have demonstrated that the spinal cord mediates the analgesic and immobility effects of inhalation anesthetics [21, 22]. The it injection in mice is an appropriate method to study spinally-mediated drug effects. According to a report by Hylden and Wilcox [10], $5 \mu 1$ of methylene blue dye never diffused beyond the rostral thoracic segments. In addition, it injected $\left[{ }^{3} \mathrm{H}\right]$ morphine was not found in significant quantities in either the midbrain or forebrain. Therefore, we determined the behavioral effects of drugs at the spinal level. In preliminary experiments, we observed that YM-31636 $(15 \mu \mathrm{g}$, it $)$ treatment increased scratching behavior. However, in this experiment, the doses used had no effect on behavior. Many studies have demonstrated that 5-HT released from descending bulbospinal neurons exerts dual (facilitatory and inhibitory) effects on spinal nociceptive transmission - activation of $5-\mathrm{HT}_{3}$ receptors and inhibition of 5- $\mathrm{HT}_{1 \mathrm{~A}}$ receptors [18, 27]. Our study showed that YM-31636 (it) treatment significantly and dose-dependently decreased the TWL and increased the writhing time of mice treated with emulsified sevoflurane. Our data suggest that sevoflurane administration reduces current response via $5-\mathrm{HT}_{3}$ receptors. In support of our hypothesis, we conclude that spinal $5-\mathrm{HT}_{3}$ receptors may modulate the analgesic effects of emulsified sevoflurane.

\section{Acknowledgments:}

This work was supported by the National Natural Science Foundation of China (No. 30872442) and the Social Development Fund of Zhenjiang, Jiangsu Province (SH2008051, SH2007060).

\section{References:}

1. Abraham MH, Acree WE Jr, Mintz C, Payne S: Effect of anesthetic structure on inhalation anesthesia: Implications for the mechanism. J Pharm Sci, 2008, 97, 2373-2384.

2. Alves HC, Valentim AM, Olsson IA, Antunes LM: Intraperitoneal anaesthesia with propofol, medetomidine and fentanyl in mice. Lab Anim, 2009, 43, 27-33.

3. Cascio M: Modulating inhibitory ligand-gated ion channels. AAPS J, 2006, 8, E353-361.

4. Chiari PC, Pagel PS, Tanaka K, Krolikowski JG, Ludwig LM, Trillo RA Jr, Puri N et al.: Intravenous emulsified halogenated anesthetics produce acute and delayed preconditioning against myocardial infarction in rabbits. Anesthesiology, 2004, 101, 1160-1166.

5. Filip M, Bader M: Overview on 5-HT receptors and their role in physiology and pathology of the central nervous system. Pharmacol Rep, 2009, 61, 761-777. 
6. Hang L, Shao D, Yang Y, Sun W, Dai T, Zeng Y: $\alpha$-Amino-3-hydroxy-5-methyl-4-isoxazolepropionic acid receptors participate in the analgesic but not hypnotic effects of emulsified halogenated anaesthetics. Basic Clin Pharmacol Toxicol, 2008, 103, 31-35.

7. Hang LH, Shao DH, Yang YH, Dai TJ, Zeng YM: Spinal $\alpha$-amino-3-hydroxy-5-methyl-4-isoxazolepropionic acid receptors may mediate the analgesic effects of emulsified halogenated anaesthetics. Clin Exp Pharmacol Physiol, 2007, 34, 1121-1125.

8. Hemmings HC Jr, Akabas MH, Goldstein PA, Trudell JR, Orser BA, Harrison NL: Emerging molecular mechanisms of general anesthetic action. Trends Pharmacol Sci, 2005, 26, 503-510.

9. Hoyer D, Hannon JP, Martin GR: Molecular, pharmacological and functional diversity of 5-HT receptors. Pharmacol Biochem Behav, 2002, 71, 533-554.

10. Hylden JL, Wilcox GL: Intrathecal morphine in mice: A new technique. Eur J Pharmacol, 1980, 67, 313-316.

11. Ito H, Kiso T, Miyata K, Kamato T, Yuki H, Akuzawa S, Nagakura Y et al.: Pharmacological profile of YM-31636, a novel $5-\mathrm{HT}_{3}$ receptor agonist, in vitro. Eur J Pharmacol, 2000, 409, 195-201.

12. Jansen M, Bali M, Akabas MH: Modular design of Cysloop ligand-gated ion channels: functional $5-\mathrm{HT}_{3}$ and GABA $\rho 1$ receptors lacking the large cytoplasmic M3M4 loop. J Gen Physiol, 2008, 131, 137-146.

13. Kayser V, Elfassi IE, Aubel B, Melfort M, Julius D, Gingrich JA, Hamon M, Bourgoin S: Mechanical, thermal and formalin-induced nociception is differentially altered in $5-\mathrm{HT}_{1 \mathrm{~A}^{-}}-$, $5-\mathrm{HT}_{1 \mathrm{~B}}-/-, 5-\mathrm{HT}_{2 \mathrm{~A}^{-}}--, 5-\mathrm{HT}_{3 \mathrm{~A}^{-}}-$and 5-HTT-/- knock-out male mice. Pain, 2007, 130, 235-248.

14. Laursen SE, Belknap JK: Intracerebroventricular injections in mice. Some methodological refinements. J Pharmacol Methods, 1986, 16, 355-357.

15. Mantz J, Dahmani S: Exploring the mechanisms of general anesthesia. Acta Anaesthesiol Belg, 2008, 59, 167-171.

16. Mukaida K, Shichino T, Koyanagi S, Himukashi S, Fukuda $\mathrm{K}$ : Activity of the serotonergic system during isoflurane anesthesia. Anesth Analg, 2007, 104, 836-839.

17. Nguyen HT, Li KY, daGraca RL, Delphin E, Xiong M, Ye JH: Behavior and cellular evidence for propofolinduced hypnosis involving brain glycine receptors. Anesthesiology, 2009, 110, 326-332.

18. Oyama T, Ueda M, Kuraishi Y, Akaike A, Satoh M: Dual effect of serotonin on formalin-induced nociception in the rat spinal cord. Neurosci Res,1996, 25, 129-135.

19. Perouansky M: Non-immobilizing inhalational anestheticlike compounds. Handb Exp Pharmacol, 2008, 209-223.

20. Peters JA, Hales TG, Lambert JJ: Molecular determinants of single-channel conductance and ion selectivity in the cys-loop family: Insights from the $5-\mathrm{HT}_{3}$ receptor. Trends Pharmacol Sci, 2005, 26, 587-594.

21. Rampil IJ: Anesthetic potency is not altered after hypothermic spinal cord transection in rats. Anesthesiology, 1994, 80, 606-610.
22. Rampil IJ, Mason P, Singh H: Anesthetic potency (MAC) is independent of forebrain structures in the rat. Anesthesiology, 1993, 78, 707-712.

23. Solt K, Forman SA: Correlating the clinical actions and molecular mechanisms of general anesthetics. Curr Opin Anaesthesiol, 2007, 20, 300-306.

24. Sonner JM, Werner DF, Elsen FP, Xing Y, Liao M, Harris RA, Harrison NL et al.: Effect of isoflurane and other potent inhaled anesthetics on minimum alveolar concentration, learning, and the righting reflex in mice engineered to express alphal gamma-aminobutyric acid type a receptors unresponsive to isoflurane. Anesthesiology, 2007, 106, 107-113.

25. Stevens RJ, Rüsch D, Davies PA, Raines DE: Molecular properties important for inhaled anesthetic action on human 5-HT 3 A receptors. Anesth Analg, 2005, 100, 1696-1703.

26. Stevens R, Rüsch D, Solt K, Raines DE, Davies PA: Modulation of human 5-hydroxytryptamine type $3 \mathrm{AB}$ receptors by volatile anesthetics and n-alcohols. J Pharmacol Exp Ther, 2005, 314, 338-345.

27. Suzuki R, Morcuende S, Webber M, Hunt SP, Dickenson AH: Superficial NK1-expressing neurons control spinal excitability through activation of descending pathways. Nat Neurosci, 2002, 5, 1319-1326.

28. Suzuki T, Koyama H, Sugimoto M, Uchida I, Mashimo T: The diverse actions of volatile and gaseous anesthetics on human-cloned 5-hydroxytryptamine 3 receptors expressed in Xenopus oocytes. Anesthesiology, 2002, 96, 699-704.

29. Urban B: Current assessment of targets and theories of anaesthesia. Br J Anaesth, 2002, 89, 167-183.

30. Urban BW: The site of anesthetic action. Handb Exp Pharmacol, 2008, 3-29.

31. Vilela FC, de Mesquita Padilha M, Dos Santos-E-Silva L, Alves-da-Silva G, Giusti-Paiva A: Evaluation of the antinociceptive activity of extracts of Sonchus oleraceus L. in mice. J Ethnopharmacol, 2009, 124, 306-310.

32. Westphalen RI, Hemmings HC Jr: Volatile anesthetic effects on glutamate versus GABA release from isolated rat cortical nerve terminals: Basal release. J Pharmacol Exp Ther, 2006, 316, 208-215.

33. Westphalen RI, Krivitski M, Amarosa A, Guy N, Hemmings HC Jr: Reduced inhibition of cortical glutamate and GABA release by halothane in mice lacking the $\mathrm{K}^{+}$ channel, TREK-1. Br J Pharmacol, 2007, 152, 939-945.

34. Yang XL, Ma HX, Yang ZB, Liu AJ, Luo NF, Zhang WS, Wang $L$ et al.: Comparison of minimum alveolar concentration between intravenous isoflurane lipid emulsion and inhaled isoflurane in dogs. Anesthesiology, 2006, 104, 482-487.

35. Zhou JX, Luo NF, Liang XM, Liu J: The efficacy and safety of intravenous emulsified isoflurane in rats. Anesth Analg, 2006, 102, 129-134.

Received:

July 23, 2009; in revised form: December 4, 2009. 